\title{
Influência de fatores edáficos sobre variações florísticas na Floresta Estacional Semidecídua no entorno da Lagoa Carioca, Parque Estadual do Rio Doce, MG, Brasil
}

\author{
Virginia Londe de Camargos ${ }^{1,3}$, Alexandre Francisco da Silva ${ }^{1}$, João Augusto Alves Meira Neto ${ }^{1}$ e \\ Sebastião Venâncio Martins²
}

Recebido em 14/08/2006. Aceito em 2/05/2007

\begin{abstract}
RESUMO - (Influência de fatores edáficos sobre variações florísticas na Floresta Estacional Semidecídua no entorno da Lagoa Carioca, Parque Estadual do Rio Doce, MG, Brasil). O presente trabalho teve como objetivos determinar se a distribuição de espécies arbóreas e

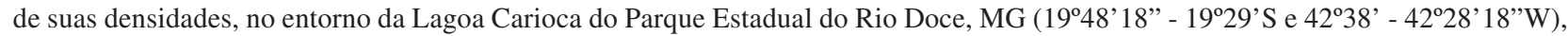
poderiam estar correlacionadas com fatores edáficos e indicar espécies para a recuperação de matas ciliares. Foram alocados dois blocos de 50 parcelas de $10 \times 10 \mathrm{~m}$, sendo um em relevo de menor declividade e outro de maior declividade. Forma amostrados todos os indivíduos com circunferência do tronco a $130 \mathrm{~cm}$ do solo (CAP) maior ou igual a $15 \mathrm{~cm}$. Foi coletada uma amostra simples de solo por parcela na profundidade de 0 a $20 \mathrm{~cm}$. A partir de grupos de dez parcelas formou-se uma amostra composta, que foi submetida à análise química e granulométrica. A ordenação dos dados de solo e vegetação foi realizada pela análise de correspondência canônica (CCA) que indicou serem os fatores edáficos os responsáveis pela ordenação das espécies. Xylopia emarginata Mart., Calophyllum brasiliense Cambess., Tapirira guianensis Aubl., Tabebuia chrysotricha (Mart. ex Dc.) Standl., Protium heptaphyllum (Aubl.) Marchal e Cecropia hololeuca Miq. ocorreram restritamente na área de depleção ciliar e foram indicadas para reflorestamento de matas ciliares, uma vez que apresentaram grande resistência e predileção por ambientes úmidos.
\end{abstract}

Palavras-chave: CCA, relação solo-vegetação, matas ciliares

\begin{abstract}
Influence of soil factors on floristic variation in a Semideciduous Seasonal Forest on the shores of Carioca Lake, Rio Doce State Park, Minas Gerais State, Brazil). The aim of this work was to determine if tree species distribution and density in the area

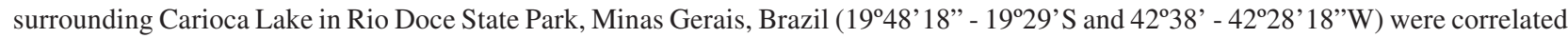
with soil factors and to designate species for the recovery of riverine forests. Two blocks of 50 plots, $10 \times 10 \mathrm{~m}$ each, were set up, one on a steep slope and the other on a gentle slope. All trees with trunk circumference at $130 \mathrm{~cm}$ above ground (cbh) equal to or greater than $15 \mathrm{~cm}$ were sampled. A total of 10 composite soil samples formed by 10 single samples were collected at $0-20 \mathrm{~cm}$ depth. These were submitted to chemical and granulometric analysis and moisture content was calculated. The ordination of soil and vegetation data was done by the canonic correspondence analysis (CCA) which showed that soil and drainage factors were responsible for species ordination. The species Xylopia emarginata Mart., Calophyllum brasiliense Cambess., Tapirira guianensis Aubl., Tabebuia chrysotricha (Mart. ex Dc.) Standl., Protium heptaphyllum (Aubl.) Marchal and Cecropia hololeuca Miq. occurred only in degraded riverine areas and were recommended for riverine reforestation, since they are very hardy and prefer moist environments.
\end{abstract}

Key words: CCA, soil-vegetation relationship, riverine forest

\section{Introdução}

As florestas ribeirinhas desempenham várias funções, destacando-se a estabilização das ribanceiras devido ao emaranhado dos sistemas radiculares; a função tampão e filtro entre terrenos mais altos e o ecossistema aquático, participando do controle do ciclo de nutrientes, por meio de ação tanto no escoamento superficial, quanto na absorção de nutrientes do escoamento subsuperficial pela vegetação ciliar, impedindo ou dificultando o carreamento de sedimentos para o sistema aquático; integração à superfície da água, proporcionando cobertura e alimentação à fauna aquática (Lima 1989).

As comparações florísticas entre remanescentes de formações florestais ciliares têm mostrado que

\footnotetext{
1 Universidade Federal de Viçosa, Departamento de Biologia Vegetal, Av. Peter Henry Rolfs, s.n., Campus Universitário, 36570-000 Viçosa, MG, Brasil

2 Universidade Federal de Viçosa, Departamento de Engenharia Florestal, Av. Peter Henry Rolfs, s.n., Campus Universitário, 36570-000 Viçosa, MG, Brasil

3 Autor para correspondência: virginialonde@yahoo.com.br
} 
essas áreas são muito diversas, com valores de similaridade muito baixos, mesmo entre áreas de grande proximidade espacial (Felfili et al. 1994; Durigan \& Leitão Filho 1995; Silva Júnior et al. 1998). A intensidade dessas diferenças são determinadas pelas características do ambiente interagindo com as características edáficas, como composição química e física dos solo, profundidade, ciclagem de nutrientes etc. Dessa forma, a dinâmica da paisagem determinou que essas formações ocupassem as condições mais favoráveis do ambiente, principalmente quanto à disponibilidade hídrica e de nutrientes, mas com grande heterogeneidade na distribuição espacial, favorecendo algumas características como a elevada diversidade (Rodrigues \& Nave 2000).

Segundo Jacomini (2000), nas áreas ocupadas pelas formações ciliares, são encontrados os mais diversos solos, os quais variam essencialmente em função do maior ou menor grau de hidromorfismo que ocorre nesses terrenos, cujos reflexos aparecem nos diversos tipos de formações florestais, variando desde terrenos mais encharcados até os mais secos, resultando em características florísticas e fisionômicas distintas.

A dinâmica da água no solo, atuando na definição das características edáficas e vegetacionais da faixa ciliar, mostra uma atuação integrada e dependente. Porém, vários trabalhos têm mostrado a atuação de outros fatores na composição do mosaico vegetacional em formações ciliares, indicando que o encharcamento do solo e as conseqüentes alterações edáficas na faixa ciliar, não são os únicos e, muitas vezes, nem os mais importantes fatores definidores das características e da dinâmica das florestas ciliares (Rodrigues \& Shepherd 2000).

Variações na estrutura e composição florística em função do solo já foram detectadas, mas faltam informações de correlações específicas entre os diversos tipos de solos e as diversas variações das formações florestais, principalmente as relações específicas (Jacomine 2000). Diante disso, fazem-se necessários estudos de correlações específicas entre os diversos tipos de solo e as formações florestais. $\mathrm{O}$ presente trabalho teve como objetivo verificar se a distribuição de espécies arbóreas e de suas densidades, às margens de uma lagoa no Parque Estadual do Rio Doce (PERD), pode estar correlacionada com fatores edáficos, e se existem espécies de ocorrência restrita à área de depleção ciliar que poderiam ser indicadas para a recuperação de matas ciliares e margens de reservatórios de usinas hidrelétricas.

\section{Material e métodos}

O trabalho foi realizado no Parque Estadual do Rio Doce (PERD) (19 48'18' $-19^{\circ} 29^{\prime} \mathrm{S}$ e $42^{\circ} 38^{\prime}$ $\left.42^{\circ} 28^{\prime} 18^{\prime \prime} \mathrm{W}\right)$, que se encontra inserido na Depressão Interplanáltica do Vale do Rio Doce (IGA-MG 1997), tendo seus limites abrangidos pelos municípios de Dionísio, Marliéria e Timóteo, no Vale do Aço de Minas Gerais.

O PERD foi criado em 1994, mas está desde 1962 sob a administração do Instituto Estadual de Florestas de Minas Gerais. Abriga um complexo de 42 lagoas (SOCT/CETEC 1981) em meio a uma densa vegetação de Formação Floresta Estacional Semidecídua Montana (Veloso et al. 1991).

O relevo apresenta duas formas: as colinas, em sua maioria convexas, originadas da dissecação fluvial de superfícies de aplainamento, datadas do Terciário Superior e Pleistoceno, com altitudes variando de 230 a 515 m (IGA-MG, 1997).

O clima, de acordo com o sistema de Köppen, é do tipo Aw (tropical úmido de savana) com estacionalidade bem marcada. O período de chuvas vai de setembro a março e o período seco de abril a agosto. As médias anuais de precipitação pluvial, temperatura e umidade relativa do ar são de $1.300 \mathrm{~mm}$, $23{ }^{\circ} \mathrm{C}$ e $79 \%$, respectivamente (CENIBRA 2003).

A área de trabalho foi estabelecida na margem da lagoa Carioca por apresentar sítios com diferentes declividades, apresentando vegetação em bom estado de conservação e em regeneração apesar um incêndio ocorrido no final da década de 60 (MarcosVinícius de Freitas, comunicação pessoal).

Algumas parcelas foram alocadas em região com pouca declividade, de baixada, às margens da lagoa, inundada temporariamente no período chuvoso, e outra onde o avanço do nível d'água é pequeno devido a maior declividade. Utilizou-se o método de parcelas (Mueller-Dombois \& Ellenberg 1974). Foram alocadas 100 parcelas de $10 \times 10 \mathrm{~m}$ totalizando $10.000 \mathrm{~m}^{2}$. As 100 parcelas foram distribuídas em dois blocos de 50 parcelas, sendo um com menor declividade e outro com maior declividade, procurando amostrar as variações de relevo a partir da margem da lagoa. Nestes blocos, 20 parcelas foram marcadas em áreas totalmente alagadas no período de dezembro a março (Fig. 1).

Foram amostrados indivíduos arbóreos vivos e mortos ainda em pé, que apresentavam circunferência de tronco, a $130 \mathrm{~cm}$ do solo (CAP), maior ou igual a $15 \mathrm{~cm}$.

A identificação do material botânico foi realizada mediante consulta da literatura especializada e 


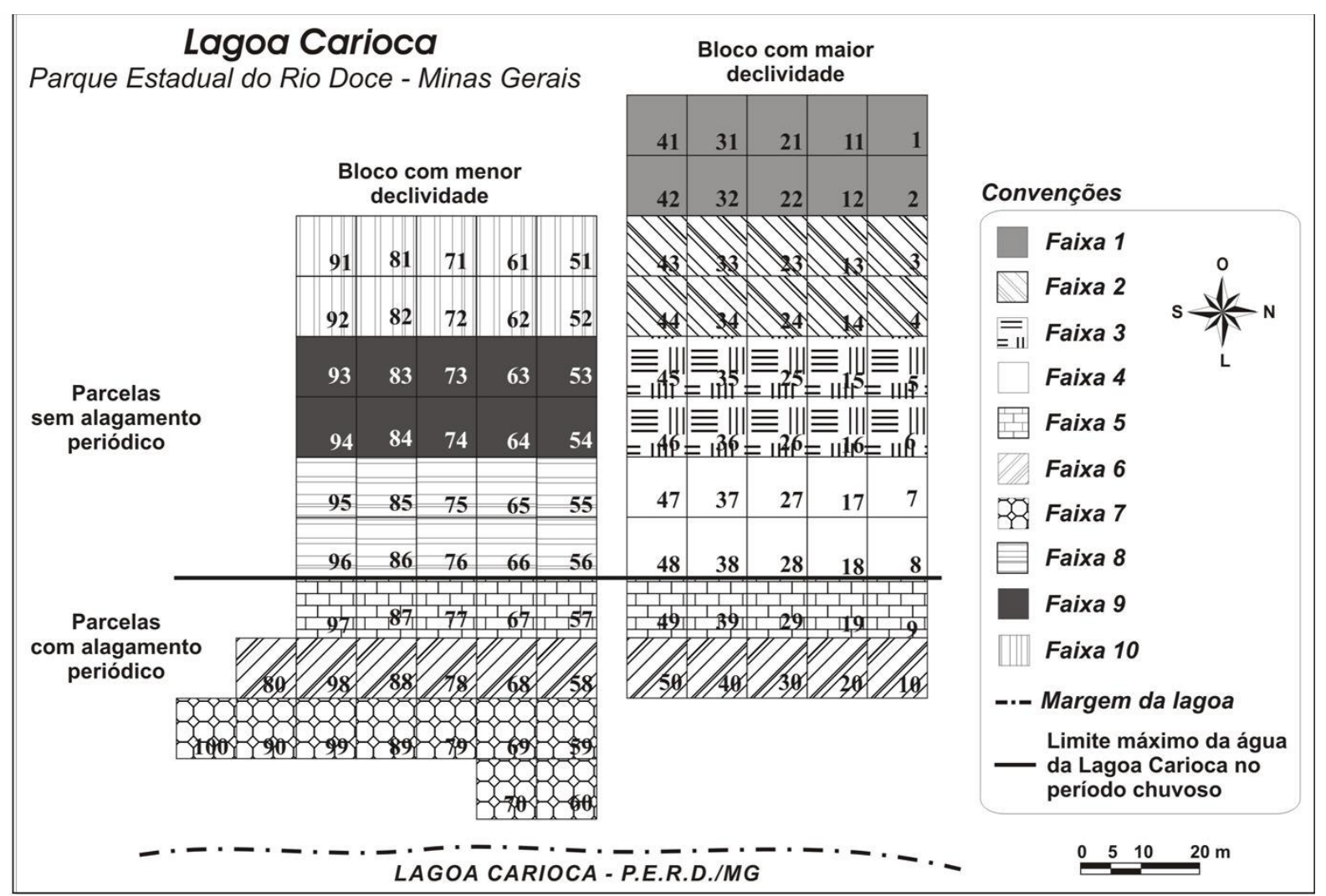

Figura 1. Distribuição das parcelas no entorno da lagoa Carioca no Parque Estadual do Rio Doce, Minas Gerais, Brasil mostrando as faixas onde foram coletadas as amostras de solos.

comparações com material do Herbário do Departamento de Biologia Vegetal, da Universidade Federal de Viçosa (VIC) e de consultas a especialistas quando necessário. Para a organização sistemática da florística foi adotado o Sistema de Cronquist (1981), excetuando-se a família Leguminosae, para a qual se manteve as três subfamílias. A confirmação dos nomes, bem como de seus autores, foi obtida consultando o índice de espécies do programa Index Kewensis 2.0 (Royal Botanic Gardens 1997), o site Missouri Botanical Garden (http://www.mobot.org/w3t/search/ vast.html), ou em literaturas mais atualizadas.

Para as análises físicas e químicas dos solos foram utilizadas 10 amostras compostas, conforme mostra a Fig. 1, formadas por 10 amostras simples, coletadas com o auxílio de um trado holandês na profundidade de 0 a $20 \mathrm{~cm}$. Essas amostras são tratadas aqui também como faixas onde ocorreram as espécies utilizadas para a análise de correspondência canônica.

As amostras foram analisadas no Departamento de Solos da Universidade Federal de Viçosa, tendo sido analisados o $\mathrm{pH}$ em água, o fósforo $(\mathrm{P})$ e o potássio (K) disponíveis, o cálcio $\left(\mathrm{Ca}^{2+}\right)$, o magnésio $\left(\mathrm{Mg}^{2+}\right)$, alumínio $\left(\mathrm{Al}^{3+}\right)$, o hidrogênio + alumínio $(\mathrm{H}+\mathrm{Al})$, a soma de bases (SB), o índice de saturação por alumínio $(\mathrm{m})$, a capacidade de troca catiônica efetiva [CTC $(\mathrm{t})$ ], a capacidade de troca catiônica a pH 7,0 [(CTC (T)), o índice de saturação por bases (V) e o teor de matéria orgânica (MO). Realizou-se também análise granulométrica (porcentagem de areia grossa, areia fina, silte e argila). Todas as análises seguiram os procedimentos do Manual de Métodos de Análise de Solo (EMBRAPA 1997).

A interpretação dos resultados da análise química do solo (Tab. 3) foi estabelecida de acordo com Tomé Júnior (1997) e Alvarez et al. (1999).

Para testar a hipótese de que existem variações na distribuição das densidades das espécies correlacionadas com fatores edáficos, foram construídas duas matrizes. A matriz principal incluiu dados de densidade absoluta (DA) das espécies (Tab. 1) obtidos da amostra fitossociológica, das parcelas onde foram realizadas as análises de solo. Foram incluídas apenas espécies amostradas com o mínimo de dez indivíduos, totalizando 35 espécies (Tab. 1), uma vez que as espécies de densidade muito 
Tabela 1. Listagem das 35 espécies arbóreas, abreviações utilizadas na análise de correspondência canônica (CCA), suas densidades totais e por faixas onde foram coletadas amostras de solo no entorno da lagoa Carioca, Parque Estadual do Rio Doce, Minas Gerais, Brasil.

\begin{tabular}{|c|c|c|c|c|c|c|c|c|c|c|c|c|}
\hline \multirow[t]{2}{*}{ Espécies } & \multirow[t]{2}{*}{ Abreviações } & \multirow{2}{*}{$\begin{array}{c}\text { Densidade } \\
\text { Total }\end{array}$} & \multicolumn{10}{|c|}{ Densidade de espécies por faixa } \\
\hline & & & 1 & 2 & 3 & 4 & 5 & 6 & 7 & 8 & 9 & 10 \\
\hline Alchornea triplinervia (Spreng.) Müll. Arg. & Alc trip & 19 & 0 & 0 & 0 & 0 & 5 & 0 & 0 & 7 & 4 & 3 \\
\hline Anadenanthera colubrina (Vell.) Brenan & Ana col & 42 & 9 & 13 & 0 & 4 & 4 & 0 & 0 & 3 & 3 & 6 \\
\hline Aniba firmula (Nees \& C. Mart.) Mez. & Ani fir & 18 & 4 & 2 & 2 & 1 & 4 & 4 & 0 & 1 & 0 & 0 \\
\hline Annona cacans Warm. & Ann cac & 10 & 0 & 2 & 0 & 4 & 2 & 0 & 0 & 0 & 2 & 0 \\
\hline Aparisthimium cordatum (A. Juss.) Baill. & Apa cor & 24 & 2 & 2 & 6 & 4 & 4 & 0 & 0 & 1 & 5 & 0 \\
\hline Bathysa australis (A. St.Hil.) Benth. \& Hook. f. & Bat aus & 10 & 0 & 0 & 0 & 0 & 0 & 0 & 0 & 3 & 2 & 5 \\
\hline Bauhinia longifolia D. Dietr. & Bau lon & 62 & 0 & 1 & 4 & 9 & 4 & 0 & 0 & 10 & 11 & 20 \\
\hline Bixa arborea Huber & Bix arb & 31 & 1 & 11 & 9 & 9 & 0 & 0 & 0 & 0 & 1 & 0 \\
\hline Calophyllum brasiliense Cambess. & Cal bra & 35 & 0 & 0 & 0 & 0 & 0 & 16 & 19 & 0 & 0 & 0 \\
\hline Carpotroche brasiliensis (Raddi) Endl. & Car bra & 17 & 1 & 2 & 3 & 6 & 0 & 0 & 0 & 0 & 0 & 5 \\
\hline Casearia arborea (Rich.) Urb. & Cas arb & 17 & 9 & 0 & 0 & 1 & 0 & 0 & 0 & 0 & 1 & 0 \\
\hline C. decandra Jacq. & Cas dec & 11 & 9 & 0 & 0 & 1 & 0 & 0 & 0 & 0 & 1 & 0 \\
\hline C. ulmifolia Vahl ex Vent. & Cas ulm & 12 & 1 & 4 & 0 & 4 & 1 & 0 & 0 & 0 & 1 & 1 \\
\hline Cecropia hololeuca Miq. & Cec hol & 17 & 0 & 1 & 6 & 0 & 0 & 4 & 6 & 0 & 0 & 0 \\
\hline Eugenia florida D.C. & Eug flo & 10 & 1 & 3 & 0 & 1 & 2 & 2 & 0 & 1 & 0 & 0 \\
\hline Euterpe edulis Mart. & Eut edu & 35 & 0 & 1 & 4 & 3 & 6 & 0 & 0 & 15 & 4 & 2 \\
\hline Guapira hirsuta (Choisy) Lundell & Gua hir & 30 & 1 & 1 & 1 & 2 & 4 & 0 & 0 & 13 & 8 & 0 \\
\hline G. opposita (Vell.) Reitz & Gua opp & 14 & 0 & 2 & 4 & 2 & 0 & 1 & 0 & 3 & 2 & 0 \\
\hline Guatteria schomburgkiana Mart. & Gua sch & 109 & 8 & 8 & 9 & 5 & 4 & 0 & 0 & 18 & 38 & 19 \\
\hline Hortia arborea Engl. & Hor arb & 19 & 5 & 6 & 4 & 4 & 0 & 0 & 0 & 0 & 0 & 0 \\
\hline Joannesia princeps Vell. & Joa pri & 14 & 2 & 0 & 3 & 5 & 0 & 0 & 0 & 1 & 2 & 1 \\
\hline Lacistema pubescens Mart. & Lac pub & 124 & 2 & 7 & 6 & 10 & 8 & 6 & 0 & 26 & 33 & 26 \\
\hline Licania spicata Holk. f. & Lic spi & 10 & 1 & 1 & 3 & 2 & 0 & 0 & 0 & 2 & 0 & 1 \\
\hline Myrcia fallax (Rich.) DC. & Myr fal & 26 & 2 & 0 & 1 & 5 & 1 & 0 & 0 & 1 & 4 & 12 \\
\hline Ocotea paulensis Vattimo & Oco pau & 13 & 2 & 1 & 3 & 5 & 0 & 0 & 0 & 0 & 0 & 2 \\
\hline Ormosia arborea (Vell.) Harms & Osm arb & 28 & 1 & 1 & 1 & 2 & 5 & 0 & 0 & 2 & 8 & 8 \\
\hline Pera lenadri Baill. & Per lea & 31 & 0 & 3 & 4 & 3 & 6 & 1 & 0 & 7 & 4 & 3 \\
\hline Pouteria bullata (S. Moore) Baehni & Pou bul & 14 & 2 & 0 & 1 & 5 & 4 & 0 & 0 & 0 & 1 & 1 \\
\hline Protium heptaphyllum (Aubl.) & Pro hep & 13 & 0 & 0 & 0 & 0 & 3 & 5 & 5 & 0 & 0 & 0 \\
\hline Siparuna guianensis Aubl. & Sip gui & 56 & 11 & 3 & 6 & 4 & 4 & 1 & 2 & 12 & 7 & 6 \\
\hline Sloanea guianensis (Aubl.) Benth. & Slo gui & 51 & 1 & 7 & 21 & 16 & 2 & 0 & 0 & 0 & 3 & 1 \\
\hline Tabebuia chrysotrichia (Mart. ex DC.) Standl. & Tab chr & 10 & 2 & 0 & 0 & 0 & 2 & 2 & 2 & 1 & 1 & 0 \\
\hline Tapirira guianensis Aubl. & Tap gui & 34 & 4 & 0 & 1 & 4 & 5 & 12 & 7 & 0 & 1 & 0 \\
\hline Trichilia pallida Sw. & Tri pal & 14 & 0 & 1 & 0 & 2 & 4 & 0 & 0 & 2 & 0 & 5 \\
\hline Xylopia emarginata Mart. & Xyl ema & 207 & 0 & 0 & 0 & 0 & 2 & 94 & 111 & 0 & 0 & 0 \\
\hline
\end{tabular}

baixa aumentam o volume de cálculos e interferem pouco nos resultados (Ter Braak 1987).

A matriz de variáveis ambientais incluiu fósforo $(\mathrm{P})$, potássio $(\mathrm{K})$, magnésio $(\mathrm{Mg})$, alumínio mais hidrogênio $(\mathrm{H}+\mathrm{Al})$, matéria orgânica $(\mathrm{MO})$ e drenagem dos solos (Drenagem). A classe de drenagem dos solos foi expressa como variável ordinal, conforme Botrel et al. (2002) da seguinte forma: 1 - muito mal , 2 - mal, 3 - imperfeitamente, 4 - moderadamente, 5 - bem e 6 - acentuadamente drenado. Foram eliminadas variáveis consideradas redundantes e fracamente correlacionadas com as outras variáveis. O resultado da análise granulométrica não foi considerado, uma vez que não apresentou variação significativa.

Para analisar as correlações entre os gradientes ambientais e vegetacionais, foi utilizada a análise de correspondência canônica (CCA), empregando-se o programa PC-ORD (McCune \& Mefford 1997). A CCA possibilita uma análise de ordenação direta de gradientes, explicando a distribuição das espécies em relação à variáveis ambientais.

Utilizou-se o teste de permutação Monte Carlo para avaliar o nível de significância do principal eixo de ordenação canônica, podendo-se avaliar a probabilidade de acertos nas relações encontradas entre as variáveis vegetais e as ambientais (Ter Braak \& Prentice 1988). 
Tabela 2. Análise textural das amostras superficiais $(0-20 \mathrm{~cm})$ de solo coletadas nas faixas instaladas no entorno da lagoa Carioca, Parque Estadual do Rio Doce, Minas Gerais, Brasil.

Faixas Areia grossa Areia Fina Silte Argila Classe textural

\begin{tabular}{rrrrrl}
\hline 1 & 17 & 8 & 11 & 64 & Muito argilosa \\
2 & 18 & 8 & 10 & 64 & Muito argilosa \\
3 & 21 & 10 & 9 & 60 & Muito argilosa \\
4 & 20 & 10 & 10 & 60 & Muito argilosa \\
5 & 14 & 0 & 23 & 63 & Muito argilosa \\
6 & 23 & 7 & 11 & 59 & Argilosa \\
7 & 23 & 5 & 15 & 57 & Argiosa \\
8 & 11 & 5 & 14 & 70 & Muito argilosa \\
9 & 18 & 9 & 10 & 63 & Muito argilosa \\
10 & 6 & 3 & 15 & 76 & Muito argilosa \\
\hline
\end{tabular}

\section{Resultados e discussão}

A análise granulométrica dos solos (Tab. 2) apresentou predominantemente a textura muito argilosa, aparecendo em $80 \%$ das amostras. A textura argilosa apareceu nas duas amostras extraídas das parcelas no entorno da Lagoa, onde ocorre inundação no período chuvoso. Segundo Rizzini (1997), a argila é a parte mineral do solo mais importante, uma vez que o estado coloidal lhe faculta a propriedade de adsorver cátions e ânions, e de reter bases e água, e os solos ricos em argila são em muitas vezes encharcados e lamacentos, e mais compactados.

Resende et al. (1988) afirmaram que, nos solos com topografia íngreme, as perdas e os ganhos são grandes diante das elevadas taxas de erosão superficial. Muitas vezes o escoamento superficial do excesso hídrico promove a remoção das partículas mais leves do solo, que são depositadas na parte mais baixa da encosta, fazendo surgir um gradiente de textura mais fina encosta abaixo.

Observou-se que as amostras 4, 6 e 7 apresentaram maiores concentrações de matéria orgânica (MO) 7, 16, 7,16 e 7,78 dag/kg respectivamente (Tab. 3). Estes valores são considerados altos e indicam um solo rico em matéria orgânica. Segundo Tomé Júnior (1997), locais ricos em matéria orgânica ocorrem em baixadas com excesso de água (deficiência de oxigenação), sendo mais prejudiciais para os microorganismos decompositores do que para as plantas produtoras de biomassa. A adição passa a ser maior que a perda, ocorrendo, portanto, acúmulo de matéria orgânica.

Todas as amostras apresentaram acidez elevada, uma vez que os valores considerados baixos ficaram entre 4,17 e 4,86. Os teores de fósforo (P) também foram considerados baixos $(0,5$ a 1,2$)$ ficando pouco mais elevados nas amostras retiradas das faixas próximas da lagoa. Essa acidez elevada dos solos está diretamente relacionada com a deficiência de fósforo, indicando solos de baixa fertilidade. Resende et al. (1988) afirmaram que é comum que a fertilidade química dos solos de uma catena cresça do topo para a base da encosta, o que também coincide com um aumento do conteúdo de água. Para esses mesmos autores, estudos têm confirmado que $65,1 \%$ dos solos tropicais são fortemente deficientes em P e 26,6\% são ainda medianamente deficientes e que as quantidades desse elemento absorvidas pelas plantas são relativamente baixas, quando comparadas àquelas relativas ao nitrogênio e ao potássio.

Tabela 3. Características químicas das amostras de solos coletadas nas faixas instaladas no entorno da lagoa Carioca do Parque Estadual do Rio Doce, Minas Gerais, Brasil.

\begin{tabular}{|c|c|c|c|c|c|c|c|c|c|c|c|c|c|c|}
\hline \multirow[t]{2}{*}{ Faixas } & \multirow{2}{*}{$\begin{array}{c}\mathrm{pH} \\
\left(\mathrm{H}_{2} \mathrm{O}\right)\end{array}$} & $\mathrm{P}$ & $\mathrm{K}$ & $\mathrm{Ca}^{2+}$ & $\mathrm{Mg}^{2+}$ & $\mathrm{Al}^{3+}$ & $\mathrm{H}+\mathrm{Al}$ & $\mathrm{SB}^{1}$ & $(t)^{2}$ & $(T)^{3}$ & $\mathrm{~V}^{4}$ & $\mathrm{M}^{5}$ & \multirow{2}{*}{$\frac{\mathrm{MO}^{6}}{\mathrm{Dag} / \mathrm{Kg}}$} & \multirow{2}{*}{$\frac{\text { P-rem }}{7}$} \\
\hline & & \multicolumn{2}{|c|}{$\mathrm{Mg} / \mathrm{dm}^{3-}$} & \multicolumn{4}{|c|}{$\mathrm{cmol} / \mathrm{dm}^{3}$} & \multicolumn{3}{|c|}{$\mathrm{cmol}_{\mathrm{c}} / \mathrm{dm}^{3}$} & \multicolumn{2}{|c|}{$\%$} & & \\
\hline 1 & 4,33 & 0,6 & 27 & 0,10 & 0,06 & 2,00 & 9,6 & 0,23 & 2,23 & 9,83 & 2,3 & 89,7 & 5,27 & 28,2 \\
\hline 2 & 4,17 & 0,8 & 31 & 0,20 & 0,11 & 2,20 & 9,9 & 0,39 & 2,59 & 10,29 & 3,8 & 84,9 & 5,65 & 28,2 \\
\hline 3 & 4,37 & 0,5 & 26 & 0,13 & 0,08 & 1,60 & 7,6 & 0,28 & 1,88 & 7,88 & 3,6 & 85,1 & 4,65 & 27,3 \\
\hline 4 & 4,46 & 0,8 & 24 & 1,08 & 0,27 & 2,00 & 9,6 & 1,41 & 3,41 & 11,01 & 12,8 & 58,7 & 7,16 & 29,9 \\
\hline 5 & 4,37 & 1,0 & 20 & 0,14 & 0,09 & 1,80 & 9,2 & 0,28 & 2,08 & 9,48 & 3,0 & 86,5 & 2,13 & 25,2 \\
\hline 6 & 4,70 & 1,2 & 19 & 0,23 & 0,15 & 1,60 & 18,2 & 0,43 & 2,03 & 18,63 & 2,3 & 78,8 & 7,16 & 17,2 \\
\hline 7 & 4,86 & 0,6 & 15 & 0,07 & 0,03 & 1,20 & 14,9 & 0,14 & 1,34 & 15,04 & 0,9 & 89,6 & 7,78 & 27,1 \\
\hline 8 & 4,31 & 0,9 & 29 & 0,55 & 0,24 & 2,20 & 9,6 & 0,86 & 3,06 & 10,46 & 8,2 & 71,9 & 6,53 & 27,6 \\
\hline 9 & 4,30 & 0,7 & 30 & 0,14 & 0,04 & 2,20 & 9,6 & 0,26 & 2,46 & 9,86 & 2,6 & 89,4 & 5,78 & 29,6 \\
\hline 10 & 4,30 & 0,8 & 22 & 1,86 & 0,52 & 2,00 & 8,6 & 2,44 & 4,44 & 11,04 & 22,1 & 45,0 & 6,53 & 31,8 \\
\hline
\end{tabular}

${ }^{1}$ soma das bases trocáveis; ${ }^{2}$ capacidade de troca catiônica efetiva; ${ }^{3}$ capacidade de troca catiônica a pH 7,0; ${ }^{4}$ índice de saturação de bases; ${ }^{5}$ índice de saturação de alumínio; ${ }^{6}$ matéria orgânica; ${ }^{7}$ fósforo remanescente. 
Para o potássio $(\mathrm{K})$, os teores também foram considerados baixos e a capacidade de troca de cátions (CTC) foi muito alta. Potássio, CTC e textura do solo estão diretamente relacionados. O nível de potássio trocável adequado às plantas é mais elevado em solos argilosos e com maior CTC, do que em solos arenosos com baixa CTC.

Há uma tendência de ocorrerem maiores teores de $\mathrm{H}+\mathrm{Al}$ em solos mais ricos em matéria orgânica, principalmente se estes apresentarem $\mathrm{pH}$ baixo. Esse fato foi comprovado analisando os teores de $\mathrm{H}+\mathrm{Al}$, que praticamente dobraram seus valores nas amostras 6 e 7, onde os teores de MO são maiores.

Os teores de cálcio $(\mathrm{Ca})$ e magnésio $(\mathrm{Mg})$ variaram entre baixo e médio, o alumínio (Al), entre alto e muito alto com baixa saturação por bases (V), indicando existir elevada acidez e provavelmente toxidez por $\mathrm{Al}^{3+}$.

De acordo com os valores de saturação por bases (menor que 50\%) e saturação por alumínio (maior que 50\%), os solos podem ser classificados como álicos e distróficos (Tomé Júnior 1997; Alvarez et al. 1999).

Segundo Jacomine (2000), sob florestas ciliares ocorre uma significativa variação de solos, cujos reflexos aparecem nos diversos tipos de formações florestais. Esta variação ocorre em terrenos mais encharcados até mais secos, onde as florestas apresentam características florísticas e fisionomias distintas. $\mathrm{O}$ autor ainda ressalta que variações em função do solo são detectadas, mas faltam informações de correlação específica entre os diversos solos e as diversas variações das formações florestais.

Os autovalores da análise de correspondência canônica (CCA) para os dois primeiros eixos de ordenação foram de 0,861 (eixo 1) e de 0,215 (eixo 2), explicando 52,0\% e 65,0\% da variância total acumulada na média ponderada das 35 espécies com respeito às variáveis ambientais. Esses valores foram considerados altos quando comparados com os resultados encontrados por Oliveira Filho et al. (1994), Botrel et al. (2002), Souza et al. (2003), Martins et al. (2003), Carvalho et al. (2005a) e Carvalho et al. (2005b), entre outros, e indicaram que as variáveis analisadas foram suficientes para explicar a ocorrência de algumas espécies restritas a determinadas faixas da amostra. Houve significância das correlações entre os eixos de espécies e de variáveis ambientais com valores de 0,998 para o eixo 1 e 0,917 para o eixo 2. As variáveis ambientais foram mais fortemente correlacionadas com o primeiro eixo, destacando em ordem decrescente $\mathrm{H}+\mathrm{Al}$, MO, classe de drenagem e K (Tab. 4). As correlações ponderadas também mostraram interrelações fortes entre as sete variáveis, destacando-se as altas correlações positivas entre $\mathrm{Ca}$ e $\mathrm{Mg}$, $\mathrm{K}$ e classe de drenagem, $\mathrm{MO}$ e $\mathrm{H}+\mathrm{Al}$, e, correlações negativas entre classe de drenagem e $\mathrm{H}+\mathrm{Al}$, $\mathrm{K}$ e $\mathrm{H}+\mathrm{Al}$, confirmando existir uma forte associação entre a umidade do solo e acidez total. Como já foi salientado, de acordo com Tome Júnior (1997), há uma tendência de ocorrerem maiores teores de $\mathrm{H}+\mathrm{Al}$ em solos mais ricos em matéria orgânica. Além disso, o teste de permutação de Monte Carlo mostrou que a probabilidade de encontrar ao acaso um autovalor igual ou maior que o obtido pelos dois eixos de ordenação canônica, com o mesmo número de variáveis utilizadas, foi inferior a $5 \%$.

No diagrama de ordenação das faixas (Fig. 2) no primeiro eixo somente as faixas F6 e F7 foram discriminadas. Das faixas alocadas no entorno da lagoa, a F6 e a F7 foram as únicas onde há inundação no período chuvoso, e estão diretamente associadas ao

Tabela 4. Análise de correspondência canônica (CCA) da abundância de 35 espécies amostradas em 10 faixas alocadas no entorno da lagoa Carioca, Parque Estadual do Rio Doce, Minas Gerais, Brasil: correlações internas entre as variáveis edáficas e os dois primeiros eixos de ordenação e de correlações ponderadas entre as variáveis ambientais utilizadas na análise. Correlações com valores absolutos $>0,5$ estão indicados em negrito.

\begin{tabular}{|c|c|c|c|c|c|c|c|c|}
\hline \multirow[t]{2}{*}{ Variáveis ambientais } & \multicolumn{2}{|c|}{ Correlações ponderadas } & \multirow[t]{2}{*}{$\mathrm{P}$} & \multirow[t]{2}{*}{$\mathbf{K}$} & \multirow[t]{2}{*}{$\mathrm{Ca}$} & \multirow[t]{2}{*}{$\mathrm{Mg}$} & \multirow[t]{2}{*}{ MO } & \multirow[t]{2}{*}{ Drenagem } \\
\hline & Eixo 1 & Eixo 2 & & & & & & \\
\hline $\mathrm{P}$ & 0,231 & $-0,263$ & & & & & & \\
\hline K & $-\mathbf{- 0 , 8 0 3}$ & 0,080 & $-0,178$ & & & & & \\
\hline $\mathrm{Ca}$ & $-0,370$ & $-0,276$ & 0,111 & $-0,022$ & & & & \\
\hline $\mathrm{Mg}$ & $-0,341$ & $-0,314$ & 0,258 & $-0,009$ & $\mathbf{0 , 9 7 2}$ & & & \\
\hline MO & $\mathbf{0 , 5 2 0}$ & $-0,154$ & 0,037 & $-0,302$ & 0,240 & 0,212 & & \\
\hline Drenagem & $-0,855$ & 0,289 & $-0,423$ & $\mathbf{0 , 7 0 7}$ & 0,378 & 0,315 & $-0,389$ & \\
\hline $\mathrm{H}+\mathrm{Al}$ & 0,933 & $-0,034$ & $\mathbf{0 , 5 0 7}$ & $-0,648$ & $-0,328$ & $-0,263$ & 0,541 & $-0,827$ \\
\hline
\end{tabular}




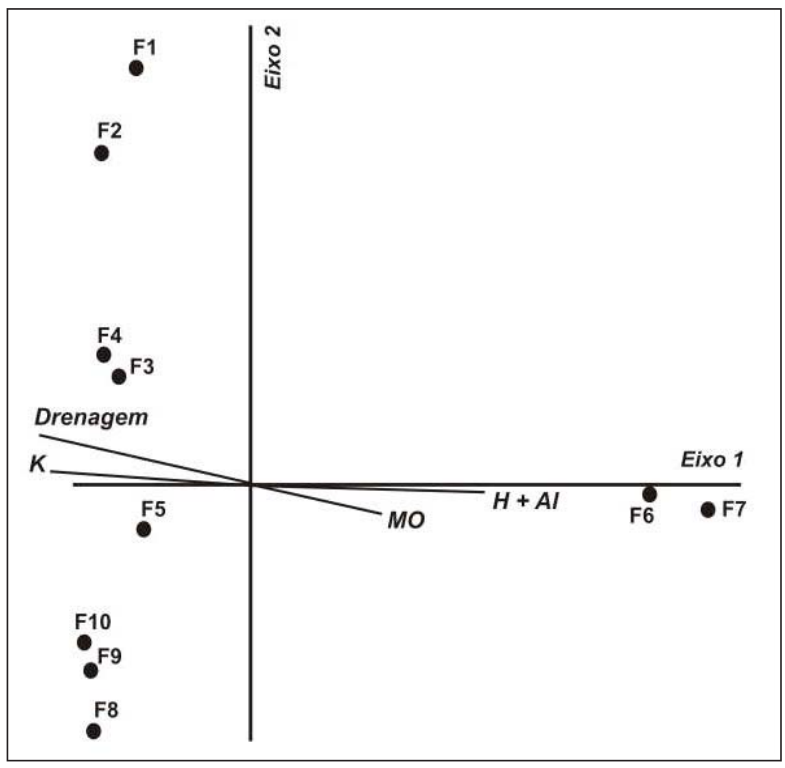

Figura 2. Diagrama de ordenação das faixas F1 até F10 (Fig. 1) produzido pela análise de correspondência canônica, baseada na distribuição da densidade das 35 espécies arbóreas com 10 ou mais indivíduos no entorno da lagoa Carioca, Parque Estadual do Rio Doce, Minas Gerais, Brasil. As variáveis edáficas estão representadas por vetores, Drenagem, $\mathrm{K}=$ potássio, $\mathrm{MO}=$ matéria orgânica, $\mathrm{H}+\mathrm{Al}$ = hidrogênio mais alumínio.

alto teor de matéria orgânica e $\mathrm{H}+\mathrm{Al}$, também apresentado neste eixo.

As faixas F8, F9 e F10 apresentaram autovalores negativos tanto para o eixo 1 quanto para o eixo 2 . Observou-se que a faixa F5 apresentou um considerável valor negativo para o eixo 1 , mas um valor muito próximo de zero para o eixo 2. Este fato pode estar relacionado com sua localização, uma vez que nesta faixa já não ocorre alagamento periódico, encontrando-se no limite desta situação.

Observou-se que as faixas F1, F2, F3 e F4 apresentaram autovalores positivos para o eixo 2 . Comparando estas faixas com as faixas F8, F9 e F10, percebe-se uma polarização e uma tendência de seus valores aumentarem no mesmo sentido que a drenagem. Analisando a localização das parcelas na Fig. 1, pode-se afirmar que a drenagem foi a grande responsável pela ordenação destas faixas, uma vez que as faixas F1, F2, F3 e F4 localizavam-se no bloco com maior declividade, sítio de boa drenagem, enquanto as faixas F8, F9 e F10 no bloco com menor declividade, conseqüentemente apresentando drenagem insuficiente.

A ordenação das espécies pela CCA (Fig. 3) sugeriu que as espécies Xylopia emarginata,

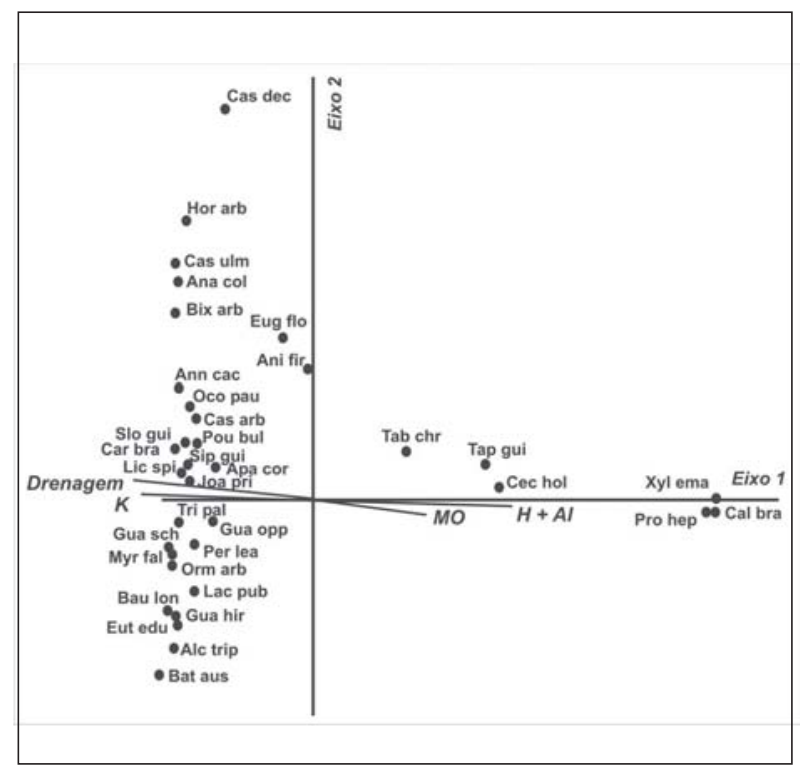

Figura 3. Diagrama de ordenação das espécies produzido pela análise de correspondência canônica, baseada na distribuição da densidade das 35 espécies arbóreas com 10 ou mais indivíduos no entorno da lagoa Carioca, Parque Estadual do Rio Doce, Minas Gerais, Brasil. As espécies estão representadas pelos nomes abreviados de acordo com a Tab. 1 e as variáveis edáficas por vetores Drenagem, $\mathrm{K}=$ potássio, $\mathrm{MO}=$ matéria orgânica, $\mathrm{H}+\mathrm{Al}$ : hidrogênio mais alumínio.

Calophyllum brasiliense, Protium heptaphylum, Cecropia hololeuca, Tapirira guianensis e Tabebuia chrysotricha tendem a ser mais abundantes nas áreas adjacentes à lagoa, com drenagem mais deficiente. Destaca-se que estas espécies somente ocorreram nas faixas F6 e F7, podendo assim serem consideradas como tolerantes à saturação hídrica e com predileção para sítios com altovalores de umidade, $\mathrm{MO}, \mathrm{H}+\mathrm{Al}$ e maior acidez total. Entre estas espécies, Tapirira guianensis e Protium heptaphyllum são reconhecidas como de ocorrência comum em matas ciliares e consideradas como generalistas por habitats (Oliveira Filho \& Ratter 2000).

As espécies Xylopia emarginata e Calophyllum brasiliense mostraram distribuição restrita à margem da lagoa onde ocorre inundação periódica. Xylopia emarginata é uma espécie que ocorre nas matas ciliares do Brasil Central, sendo compartilhada apenas com a floresta Amazônica e considerada caracteristíca de matas ciliares brejosas, por ser muito dependente de solos saturados (Oliveira Filho \& Ratter 2000), geralmente ocorre em grandes agrupamentos chegando a formar populações quase puras. A disseminação por pássaros e pela água garante sua regeneração natural em terrenos brejosos, apesar da escassa produção de 
sementes viáveis (Lorenzi 1992).

Calophyllum brasiliense é uma espécie arbórea que ocorre desde a América Central até o litoral norte catarinense (Lorenzi 1992). O sucesso adaptativo desta espécie se deve à capacidade de germinar após vários meses de submersão, embora as sementes, enquanto submersas, não germinem; suas plântulas crescem normalmente, tanto em solo inundado quanto em solo bem drenado, o que confere alta freqüência em vários ambientes ribeirinhos do sudeste do Brasil (Marques \& Joly 2000; Scarano et al. 1997). Sua dispersão é ampla, porém contínua, ocorrendo geralmente em grandes agrupamentos, formando populações quase puras. A espécie produz quase todos os anos grande quantidade de sementes viáveis (Lorenzi 1992).

No outro extremo do eixo 1, apareceram as espécies preferenciais das áreas com boa drenagem, como Bathysa australis, Bauhinia longifolia, Guatteria schomburgkiana, Ormosia arborea e Trichilia pallida. No eixo 2, as espécies com maiores valores positivos foram Bixa arborea, Carpotroche brasiliensis, Guapira hirsuta, Licania spicata, Ocotea paulensis e Sloanea guianensis, apresentando também preferência por ambiente bem drenado. Já Alchornea triplinervia, Bathysa australis, Euterpe edulis e Guapira hirsuta apresentaram os maiores valores negativos. $O$. arborea, embora aqui tenha aparecido preferencialmente em terreno com boa drenagem, tem sido encontrada em algumas florestas ribeirinhas, segundo Rodrigues \& Nave (2000).

Aniba firmula e Eugenia florida apresentaram valores negativos próximos a zero para o eixo $1 \mathrm{e}$ autovalores positivos para o eixos 2. Esse fato indicou que essas espécies são generalistas aos dois ambientes, claramente diferenciados pela CCA, o bem drenado e o com saturação hídrica rico em matéria orgânica e H+Al. Tapirira guianensis, Tabebuia chrysotricha, Protium heptaphyllum e Cecropia hololeuca tiveram distribuição concentrada nas parcelas da baixada próximas à margem, onde há grande influência da água, mas não necessariamente inundação.

Segundo Lobo \& Joly (2000), o estresse imposto pela saturação hídrica do solo apresenta um caráter fortemente seletivo. $\mathrm{O}$ alagamento elimina os espaços de ar do solo limitando as trocas gasosa com a atmosfera, e em poucas horas as raízes e os microorganismos consomem o oxigênio presente na água, criando um ambiente hipóxico ou anóxico. A duração e a frequiência da saturação hídrica do solo, definem características abióticas particulares, que afetam significativamente os processos bióticos, como a taxa de decomposição, a germinação e o recrutamento de indivíduos, definindo a distribuição espacial das espécies ao longo de um gradiente perpendicular a um curso d'água, bem como a composição e a estrutura da vegetação. Para esses autores, estudos ecofisiológicos dos mecanismos de tolerância de espécies arbóreas à inundação são ainda escassos, havendo necessidade de realização de trabalhos que abordem não só características morfológicas, anatômicas, fisiológicas e bioquímicas, mas também demografia e dinâmica populacional.

O regime hídrico, a grande quantidade de matéria orgânica e conseqüentemente o aumento de $\mathrm{H}+\mathrm{Al}$ foram os principais fatores edáficos associados à distribuição de algumas espécies deste levantamento. Vários trabalhos, como Oliveira Filho et al. (1994); Schiavini (1997); Silva Júnior (1997), van den Berg \& Oliveira Filho (2000); Botrel et al. (2002), Souza et al. (2003) e Carvalho et al. (2005a) consideraram a influência da umidade dos solos na distribuição de espécies arbóreas e nas variações fisionômicas nas florestas tropicais como o principal fator ambiental. Conclusões sobre a distribuição de espécies só devem ser generalizadas após repetições do mesmo padrão em diversas áreas, uma vez que de acordo com Botrel et al. (2002), Souza et al. (2003), Carvalho et al. (2005a) e Carvalho et al. (2005b), é necessário cautela interpretação da distribuição de espécies, em consonância com as variáveis ambientais, pois, variáveis fundamentais, como as de condições de luz e os fatores de dispersão das espécies, nem sempre são facilmente perceptíveis ou mensuráveis. Algumas espécies são sensíveis a estas variáveis de uma forma interativa e não isoladamente.

\section{Agradecimentos}

Os autores agradecem ao Programa de PósGraduação em Botânica da Universidade Federal de Viçosa (UFV), pelo apoio técnico; ao Parque Estadual do Rio Doce, pela autorização e infra-estrutura; a Pedrinho Dantas, Gustavo Vasques, Vinícius Valiates, Luiz Fernando Couto, pelo auxílio nas coletas de campo; a Walnir Gomes Ferreira Júnior, pela interpretação das análises de solo e plotagem das figuras e a todos os colegas que contribuíram com sugestões. 


\section{Referências bibliográficas}

Alvarez, V.H.; Novais, R.F.; Barros, N.F.; Cantarutti, R.B. \& Lopes, A.S. 1999. Interpretação dos resultados das análises de solo. Pp. 25-32. In: Recomendação para o uso de corretivos e fertilizantes em Minas Gerais; $5^{\text {a }}$ aproximação. (A.C. Ribeireo; P.T.G. Guimarães \& V.H. Alvarez, eds.). Viçosa, Universidade Federal de Viçosa.

Botrel, R.T.; Oliveira Filho, A.T.; Rodrigues, L.A. \& Curi, N. 2002. Influência do solo e topografia sobre as variações da composição florística e estrutura da comunidade arbórea-arbustiva de uma floresta estacional semidecidual em Ingaí, MG. Revista Brasileira de Botânica 25: 195-213.

Carvalho, D.A.C.; Oliveira Filho, A.T.; van den Berg, E.; Fontes, M.A.L.; Vilela, E.A.; Marques, J.J.G.S.M. \& Carvalho, W.A.C. 2005a. Variações florísticas e estruturais do componente arbóreo de uma floresta ombófila alto-montana às margens do rio Grande, Bocaina de Minas, MG, Brasil. Acta Botanica Brasilica 19: 91-109.

Carvalho, D.A.C.; Oliveira Filho, A.T.; Vilela, E.A.; Curi, N.; van den Berg, E.; Fontes, M.A.L. \& Botezelli, L. 2005 b. Distribuição de espécies arbóreo-arbustivas ao longo de um gradiente de solos e topografia em um trecho de floresta ripária do Rio São Francisco em Três Marias, MG, Brasil. Revista Brasileira de Botânica 28: 329-345.

CENIBRA. 2003. Dados meteorológicos da estação de Belo oriente. Belo Oriente, MG.

Cronquist, A. 1981. An Integrated System of Classification of Flowering Plants. New York, Columbia University Press.

Durigan, G. \& Leitão Filho, H.F. 1995. Florística e fitossociologia de matas ciliares do Oeste Paulista. Revista Instituto Florestal 7: 197-239.

EMBRAPA. 1997. Manual de métodos de análise de solo. 2 ed. Rio de Janeiro, Centro Nacional de Pesquisa de solos.

Felfili, J.M. 1994. Floristic composition and phytosociology of the gallery forest alongside the Gama stream in Brasília, DF, Brazil. Revista Brasileira de Botânica 17: 1-11.

IGA-MG. 1997. Mapa geomorfológico 1:500.000. Folha Belo Horizonte. Secretaria de Estado de Ciência e Tecnologia de Minas Gerais. Projeto RADAR-MG.

Jacomine, P.K.T. 2000. Solos sob matas ciliares. Pp. 27-31. In: Matas ciliares: conservação e recuperação. (R.R. Rodrigues \& H.F. Leitão Filho, eds.). São Paulo, Editora da Universidade de São Paulo, Fapesp.

Lima, E.P. 1989. Função hidrológica da mata ciliar. Pp. 26-43. In: L.M. Barbosa (coord.). Simpósio sobre Mata Ciliar. Anais do Simpósio sobre Mata Ciliar. Campinas, Fundação Cargil.

Lobo, P. C. \& Joly, C. A. 2000. Aspectos ecofisiológicos da vegetação de mata ciliar do sudeste do Brasil. Pp. 143-157. In: Matas ciliares: conservação e recuperação. (R.R. Rodrigues \& H.F. Leitão Filho, eds.). São Paulo, Editora da Universidade de São Paulo, Fapesp.

Lorenzi, H. 1992. Árvores brasileiras: Manual de identificação e cultivo de plantas arbóreas nativas do Brasil. Nova Odessa, Editora Plantarum.
Marques, M.C.M. \& Joly, C.A. 2000. Estrutura e dinâmica de uma população de Calophyllum brasiliense Camb. Em floresta higrófila do sudeste do Brasil. Revista Brasileira de Botânica 23: 107-112.

Martins, S.V.; Silva, N.R.S.; Souza, A.L. \& Meira Neto, J.A.A. 2003. Distribuição de espécies arbóreas em um gradiente topográfico de Floresta Estacional Semidecidual em Viçosa, MG. Scientia Forestalis 64: 172-181.

Mccune, B. \& Mefford, M.J. 1997. PC-ORD. Multivariate Analysis of Ecological Data, Version 3.0. Gleneden Beach, Oregon, USA, MjM Software Design.

MOBOT. Missouri Botanical Garden. Disponível em http:// www.mobot.org/W3T/search/vasthtml (Acesso em: 8/12/2003).

Mueller-Dombois, D. \& Ellenberg, H. 1974. Aims and methods of vegetation ecology. New York, John Wiley \& Sons.

Oliveira Filho, A.T.; Almeida, R.J.; Mello, J.M. \& Gavinales, M.L. 1994. Estrutura fitossociológica e variáveis ambientais em um trecho de mata ciliar do córrego dos Vilas Boas, Reserva Biológica do Poço Bonito, Lavras (MG). Revista Brasileira de Botânica 17: 67-85.

Resende, M.; Curi, N. \& Santana, D.P. 1988. Pedologia e fertilidade do solo: interações e interpretações. Brasília, Ministério da Agricultura. Lavras, UFLA/FAEPE.

Rizzini, C.T. 1997. Tratado de Fitogeografia do Brasil: aspectos ecológicos, sociológicos e florísticos. Rio de Janeiro, Âmbito Cultural Edições Ltda.

Rodrigues, R.R. \& Nave, A.G. 2000. Heterogeneidade florística das matas ciliares. Pp. 45-71. In: Matas ciliares: conservação e recuperação. (R.R. Rodrigues \& H.F. Leitão Filho, eds.). São Paulo, Editora da Universidade de São Paulo, Fapesp.

Rodrigues, R.R. \& Shepherd, G.J. 2000. Fatores condicionantes da vegetação ciliar. Pp. 101-107. In: Matas ciliares: conservação e recuperação. (R.R. Rodrigues \& H.F. Leitão Filho, eds.). São Paulo, Editora da Universidade de São Paulo, Fapesp.

Royal Botanic Gardens. 1997. Index Kewensis on compact disc. Oxford, Herbarium of the Royal Botanic Gardens Kew (CD-Rom).

Scarano, F.R.; Ribeiro, K.T.; Moraes, L.F.D. \& Lima, H.C. 1997. Plant Establishment of flooded and unflooded patches of a freshwater swamp forest in southeastern Brazil. Journal Tropical Ecology 14: 793-803.

Schiavini, I. 1997. Environmental characterization and groups of species in gallery forests. Pp. 107-113. In: International Symposiym On Assessment And Monitoring Of Forests In Tropical Dry Regions With Special Reference To Gallery Forests, 1997. Brasília. Proceedings... Brasília, UNB.

Silva Júnior, M.C. 1997. Relationships between the tree communities of the Pitoco, Monjolo and Taquara gallery forest and environmental factors. Pp. 297-298. In: International Symposiym On Assessment And Monitoring Of Forests In Tropical Dry Regions With Special Reference To Gallery Forests, 1997. Brasília. Proceedings... Brasília, UNB. 
Silva Júnior, M.C.; Felfili, J.M.; Nogueira, P.E. \& Rezende, A.V. 1998. Análise florística das matas de galeria no Distrito Federal. J.F. Ribeiro (ed.). Cerrado: matas de galeria. Planaltina, EMBRAPA-CPAC.

SOCT/CETEC. 1981. Programa de pesquisas ecológicas no Parque Estadual do Rio Doce. Belo Horizonte, Sistema Operacional de Ciência e Tecnologia; Fundação Centro Tecnológico de Minas Gerais, v.2. (Relatório final).

Souza, J.S.; Del Bom Espírito-Santo, F.; Fontesm, A.L.; Oliveira Filho, A.T. \& Botezelli, I. 2003. Análise das variações florísticas e estruturais da comunidade arbórea de um trecho de floresta semindecídua às margens do Rio Capivari, Lavras, MG. Revista Ávore 27: 185-206.
Ter Braak, C.J.F. 1987. The analysis of vegetation environment relationships by canonical correspondence analysis. Vegetatio 69: 69-67.

Ter Braak, C.J.F. \& Prentice, I.C. 1988. A theory of gradient analysis. Advances in ecological Research 18: 271-317.

Tome Júnior, J.B. 1997. Manual para interpretação de análise de solo. Guaíba, Livraria e Editora Agropecuária.

van den Berg, E. \& Oliveira Filho, A.T. 2000. Composição florística e estrutura fitossociológica de uma floresta ripária em Itutinga, MG, e comparação com outras áreas. Revista Brasileira de Botânica 23: 231-253.

Veloso, H.P.; Rangel Filho, A.L.R. \& Lima, J.C.A. 1991. Classificação da vegetação brasileira, adaptada a um sistema universal. Rio de Janeiro, IBGE, Departamento de Recursos Naturais e Estudos Ambientais. 